\title{
Prevention and treatment practices and implications for malaria control in Mukono District Uganda
}

Mbonye, A K; Bygbjerg, I C; Magnussen, P

Published in:

Journal of Biosocial Science

DOI:

$10.1017 / \mathrm{S} 0021932007002398$

Publication date:

2008

Document version

Publisher's PDF, also known as Version of record

Citation for published version (APA):

Mbonye, A. K., Bygbjerg, I. C., \& Magnussen, P. (2008). Prevention and treatment practices and implications for malaria control in Mukono District Uganda. Journal of Biosocial Science, 40(2), 283-96.

https://doi.org/10.1017/S0021932007002398 


\title{
PREVENTION AND TREATMENT PRACTICES AND IMPLICATIONS FOR MALARIA CONTROL IN MUKONO DISTRICT UGANDA
}

\author{
A. K. MBONYE*, I. C. BYGBJERG† AND P. MAGNUSSEN \\ * Ministry of Health, Department of Community Health, Kampala, Uganda, †Institute \\ of Immunology, Microbiology and International Health, University of Copenhagen and \\ $\ddagger D B L$-Centre for Health Research and Development, Department of Veterinary \\ Pathobiology, University of Copenhagen
}

\begin{abstract}
Summary. Available data in Uganda indicate a resurgence of malaria morbidity and mortality countrywide. This study assessed the burden of malaria, treatment and prevention practices in order initiate a policy debate on the scaling-up of current interventions. A triangulation of methods using a cross-sectional survey and key informant interviews was used to assess self-reported malaria at a household level in Mukono District, Uganda. A total of 5583 households were surveyed, and a high proportion (2897, 51.9\%) reported a person with malaria two weeks prior to the survey. Only 546 households $(9 \cdot 8 \%)$ owned and used insecticide-treated nets (ITNs) for malaria prevention. Similarly, only a few households $(86,1 \cdot 5 \%)$ used indoor residual spraying. Self-treatment with home-stocked drugs was high, yet there was low awareness of the effectiveness of expired drugs on malaria treatment. Self-reported malaria was associated with socioeconomic, behavioural and environmental factors, but more especially with household ownership of ITNs. These results will contribute to the current debate on identifying new approaches for scaling-up prevention interventions and effective case management, as well as selection of priority interventions for malaria control in Uganda.
\end{abstract}

\section{Introduction}

Malaria is a serious health problem that contributes greatly to morbidity and mortality in Uganda. It mainly affects pregnant women and children under 5 years of age (MOH, 1999, 2000, 2002, 2005). Surveillance reports show that the proportionate mortality ratio (PMR) due to malaria for all ages has increased progressively from $20 \cdot 2 \%$ in 1988 to $32 \cdot 1 \%$ in $2004(\mathrm{MOH}, 2005)$. Most areas in Uganda (over 95\%) experience high malaria transmission; and malaria causes $40-50 \%$ of hospital admissions and $20 \%$ of mortalities $(\mathrm{MOH}, 2005)$. Although the increase in malaria 
cases could be due to increased patient attendance and awareness about malaria; this has been mainly attributed to high transmission of malaria in previously non-malaria areas, limited access to adequate treatment in formal health care facilities, increasing resistance to anti-malarial drugs and inadequate treatment at home, where the majority of people receive their first treatment (MOH, 2002, 2005). This resurgence necessitates intensifying malaria treatment and prevention interventions.

The current policy on malaria control in Uganda advocates for malaria prevention through insecticide-treated nets (ITNs) and environmental management where possible, universal access to ACTs (artemisinin-based combination therapies) and treatment and prevention of malaria in pregnancy (MOH, 2005, 2006). The first-line treatment for malaria at all public and private facilities is artemether/lumefantrine $\left(\right.$ COARTEM $\left.^{\circledR}\right)$. In addition, the country has implemented the strategy for homebased management of fevers for children since 2002. At the international level, the Roll Back Malaria Strategy (RBM) recommends that countries should increase access to ITNs to cover $60 \%$ of pregnant women and children (RMB, 2000).

Although physical, biological, social and environmental factors play an important role in the epidemiology of malaria, the resurgence of malaria in sub-Saharan Africa has called for a paradigm shift in research to increased attention to social, cultural and environment factors (Brown, 1997). The social factors that encourage transmission of malaria include close proximity of houses to mosquito breeding sites, type of house construction that facilitates mosquito entry, failure to remove water collection points and various activities and occupations that encourage malaria transmission (Heggenhougen et al., 2003).

Malaria morbidity and mortality in Africa is complicated by self-medication, which is the most common form of treatment for malaria and other diseases (Foster, 1995). Self-treatment has been described as anything from a cool bath to a course of anti-malarial drugs (McCombie, 1996). The most common form of self-medication, however, has been found to be the purchase of drugs from a pharmacy or a drug-seller. In Congo, for example, $75 \%$ of children with fever or headache who had not been seen by a health worker had been given anti-malarial drugs by their parents (Trape, 1987). Another study in Togo found that $83 \%$ of children with fever were treated at home with chloroquine from a street market (Deming, 1989). The subject of treatment seeking for malaria has been extensively reviewed and resort to multiple sources for malaria treatment has been reported (McCombie, 1996; Amuyunzu, 1998; Nyamongo, 2001). These studies conclude that most people with malaria resort to self-medication with drugs bought from drug shops, those stocked in their homes or with traditional herbs (Kengeya et al., 1994; McCombie, 1996; Mbonye et al., 2006). Furthermore, they highlight the important role of the family in decision-making about type of care and where it is sought.

In most countries of sub-Saharan Africa, the main drug distribution supply networks are the public, private, private 'not-for-profit' and private/informal sectors (Foster, 1991). There are various reasons why people patronize pharmacies, shops and illegal drug-sellers. The main reason is the ease of purchasing drugs at these outlets and obtaining immediate treatment (Igun, 1987). Several factors such as socioeconomic status, cultural beliefs about the causes and cures of illness, access to care, cost of care and the attitude of health workers have been shown to influence the 
treatment-seeking pattern for malaria and other illnesses (Mwenesi et al., 1995; Agyepong et al., 2002; Heggenhougen et al., 2003).

In Uganda, most fevers are not treated at public health facilities. The majority of people seek care from private clinics, licensed drug shops, ordinary shops selling drugs and private practitioners (Kengeya et al., 1994; Adome \& Whyte, 1996; Anyama \& Adome, 2003). A recent study in Uganda has shown that $72 \%$ of children with fever had been given pharmaceutical drugs before they visited health units (Nshakira et al., 2002). It was noted that $75 \%$ of the medicines were bought from shops in the community while $12 \%$ were from a home stock of medicines. There is concern about the widespread use of pharmaceutical drugs due to side-effects and the possible development of resistance to organisms, especially malaria parasites (Lee \& Herzetein, 1986; Foster, 1995).

This article presents results of a study that assessed the burden of self-reported malaria at the household level, and related factors, in a highly malaria-endemic district of Uganda. The focus on the household is because action at this level could be important for malaria control. These results will contribute to the current policy debate on the scaling-up of malaria prevention and treatment interventions, as well as selection of priority interventions for effective malaria control in Uganda.

\section{Methods}

\section{Study area and population}

The study was conducted in Mukono District, central Uganda. The background characteristics of the study area have been described elsewhere (Mbonye et al., 2006). Briefly, the district has a population size of 850,900 , a population density of 179 people per square kilometre, an annual population growth rate of $2 \cdot 5 \%$ and a total fertility rate of $7 \cdot 2$ (Uganda Bureau of Statistics, 2002). The district has a rural population of $88 \%$ and is mainly inhabited by Baganda people, the largest tribe in Uganda. Apart from the Baganda, the district is inhabited by the small immigrant tribes of Basoga, Badama, Bagisu, Basamya, Banyarwanda, Jaluos, Lugbar and Balulu. The district experiences high temperatures and heavy rainfall during the months of March to May and October to November. It was selected because most areas are hyper-endemic for malaria while areas on the shores of Lake Victoria are holo-endemic (MOH, 2006). As in most areas of Uganda, Plasmodium falciparum is the common cause of malaria and is mainly transmitted by Anopheles gambiae (Talisuna et al., 2002).

\section{Study design}

A triangulation of methods consisting of a cross-sectional survey and keyinformant interviews (KIs) was used to assess the burden of malaria at the household level in the three sub-counties of Buikwe, Kimenyedde and Ngogwe in Mukono District, Uganda.

The quantitative study. The sub-counties were randomly selected from the five sub-counties that border Lake Victoria. This area was selected because it has high 
malaria transmission, as indicated earlier. Data collection took place over a two-month period between February and March 2003 when the population was experiencing intense malaria transmission.

The multi-stage sampling technique was used to select parishes as the primary sampling units. In the first-stage sampling, the three sub-counties of Buikwe, Kimenyedde and Ngogwe were randomly selected from the five sub-counties that border Lake Victoria. In the second-stage sampling, three parishes were randomly selected from the sub-counties; and all the households in the parishes were surveyed. Using a structured questionnaire, the heads of households or their spouses were interviewed. Data were obtained on the following: demographic characteristics of household members, ownership of household items, observations on type of housing, reported malaria illnesses, treatment-seeking practices and prevention practices. The required sample size of households selected was calculated assuming that malaria causes $40 \%$ of morbidity in this area $(\mathrm{MOH}, 2000)$, a study power of $80 \%$ and a level of significance of $5 \%$. In total, 5583 households were included in the sample.

A household was defined as those people living, cooking and eating together for at least one year. Interviewers targeted heads of households or their spouses since these people would be most knowledgeable on issues concerning their households. Malaria was defined as a febrile illness characterized by feeling hot with headache, joint pains and general weakness. The local term omusujja gw'ensiri (translated as 'fever caused by mosquitoes') was used to refer to malaria. This term is widely used in this region to refer to malaria (Kengeya et al., 1994; Mbonye et al., 2006). The reference period for the reported malaria episodes was two weeks prior to the survey.

The qualitative study. Key informant interviews were conducted and the following thematic areas were explored: malaria morbidity, treatment practices, stocking drugs, views on expiry of drugs, and what concerns people express when they are purchasing drugs. The KIs targeted opinion leaders, local council officials, community health workers, drug-shop owners and pregnant women. These were considered to be knowledgeable on health issues in this area; and some had a role in community mobilization and provision of services in the area. In total, $105 \mathrm{KIs}$ were conducted. The respondents were aged from 25 to 65 years: twelve were opinion leaders, 20 local council officials, 15 community health workers, 8 teachers, 5 policemen 23 drug-shop owners, and 22 pregnant women. Overall 58 were females and 47 were males. The majority of them had secondary education and a few had only primary education, especially the local council officials.

The questionnaire for the survey and the KI guide were translated from English to the local language, Luganda. Interviewers for both the quantitative and qualitative studies were graduates of social sciences with experience in field research. They were trained for a week together with the research team. After training, the questionnaires were pre-tested and revised before fieldwork. Data for the KIs were recorded in answer books. Field notes were also recorded. The KIs were conducted in a quiet place, usually under a tree, with no disturbance. On average one interview took 30-40 minutes. 


\section{Data analyses}

Quantitative data were entered using Epinfo Version 6 software and analysed using Stata version $8 \cdot 0$. Bivariate analysis was used to identify variables significantly associated with the burden of malaria at the household level. The study's hypothesis was that socioeconomic and behavioural factors were responsible for malaria morbidity at the household level. Binary logistic regression analysis was used to identify factors associated with reported malaria at the household level. Three models were constructed: the first model assessed factors associated with malaria morbidity for all households that reported any case of malaria two weeks prior to the survey; the second model assessed factors for households that reported a child with malaria; and the third model assessed factors for households that reported a pregnant woman with malaria. The focus on children and pregnant women is because these are the most vulnerable to malaria. The models were constructed using the enter method and only significant variables with $p<0.05$ were retained in the model. Because of the cluster sampling technique, the design effect at analysis was computed by taking the parish as the primary sampling unit. The design effect for all variables was above $1 \cdot 0$, indicating that cluster sampling was an appropriate design for this study. The model fit for the three models was assessed for robustness using the log-likelihood ratio test and considered sufficient if the $p$ value was less than $0 \cdot 05$.

Key informant interview data were collated and manually analysed along the following themes: malaria illnesses and causes, treatment-seeking patterns and possible reasons, use of home-stocked drugs and the effect of these, perceptions on expiry of drugs, and ways through which malaria can be controlled. Responses from KIs were manually coded and to avoid loss of data, KI data were cross-checked with field notes and where possible supplemented. During analyses, common themes were identified and divergent views recorded. In the Results section, these data are presented together with quantitative data to offer possible explanations for the observed patterns of treatment and prevention-seeking practices. An attempt was made to compare these data (both quantitative and qualitative) with other sources, especially the Uganda Demographic and Health Survey, which has the most recent data on health and diseases.

\section{Ethical issues}

The study was approved by the Danish National Committee for Biomedical Research Ethics and the Uganda National Council of Science and Technology. Verbal consent was obtained from all respondents who participated in the study.

\section{Results}

\section{The study population}

A total of 5583 households were surveyed, which was $95 \%$ of the targeted sample. At the time of the survey $22 \%$ of the respondents were male heads of households while $77 \cdot 5 \%$ were females who were wives in the households. Eighty per cent of the 
Table 1. Background characteristics of household respondents $(N=5583)$

Characteristic $n$

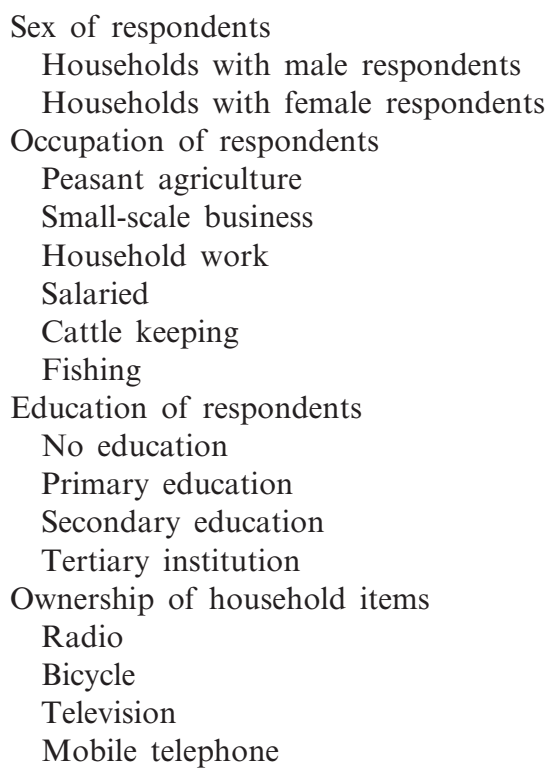

$1258(22 \cdot 5 \%)$

$4325(77 \cdot 5 \%)$

$4502(80 \cdot 6 \%)$

$412(7 \cdot 4 \%)$

$260(4 \cdot 7 \%)$

$183(3 \cdot 3 \%)$

$64(1 \cdot 2 \%)$

$118(2 \cdot 1 \%)$

$1199(21 \cdot 5 \%)$

$3249(58 \cdot 2 \%)$

$950(17 \cdot 0 \%)$

$185(3 \cdot 3 \%)$

$4291(76 \cdot 9 \%)$

$2190(39 \cdot 2 \%)$

$252(4 \cdot 5 \%)$

$181(3 \cdot 2 \%)$

respondents were engaged in peasant agriculture, which was the main source of food and income. The remaining $20 \%$ of respondents were involved in different types of activities. Other background characteristics are presented in Table 1.

The burden of malaria, treatment and prevention practices

A total of 2897 (51.9\%) households had at least one person who reported having had malaria two weeks prior to the survey. The majority of households $(1936 ; 67 \cdot 0 \%)$ reported a child with malaria, $769(26.4 \%)$ an adult, $192(6.6 \%)$ a pregnant women and $132(2 \cdot 4 \%)$ both. Among households that reported a pregnant woman with malaria, only $35(18 \cdot 2 \%)$ had visited a health unit; among those that reported a child with malaria $632(32 \cdot 8 \%)$ had visited a health unit or a private clinic for specialized care. Overall, most households obtained care for sick children from drug shops (741, $38 \cdot 3 \%$ ) and private clinics $(447,23 \cdot 1 \%)$. Most households with pregnant women with malaria resorted to self-treatment (Table 2). A few households obtained care from community health workers $(187,9 \cdot 7 \%)$, who were probably involved in the homebased management of fevers.

Chloroquine was the most common drug used at the household level to treat malaria among pregnant women and children. Thirty-seven per cent of households gave chloroquine to their children and $21 \%$ gave it to pregnant women who had malaria (data not shown). 
Table 2. Current treatment practices for malaria

Malaria at the household level

$n$

Households reporting a case of malaria

$2897 / 5583(51 \cdot 9 \%)$

Households reporting a child aged $<5$ years with malaria

$1936 / 2897(67 \cdot 0 \%)$

Households reporting a pregnant women with malaria

Treatment practices by households that reported a child with malaria, $N=1936$

Drugs from shop

$741(38 \cdot 3 \%)$

Visited a private clinic

Visited a health unit

$447(23 \cdot 1 \%)$

Visited community health workers

$185(9 \cdot 7 \%)$

$187(9 \cdot 6 \%)$

Used home-stocked drugs

$134(6 \cdot 9 \%)$

Tepid sponging

$161(8 \cdot 3 \%)$

Use of local herbs

$52(2 \cdot 7 \%)$

Nothing

$29(1 \cdot 4 \%)$

Treatment practices by households that reported pregnant women with malaria, $N=192$

Drugs from shop

$62(32 \cdot 3 \%)$

Tepid sponging

Visited a health unit

$35(10 \cdot 4 \%)$

Used home-stocked drugs

$20(18 \cdot 2 \%)$

Visited a private clinic

$24(12 \cdot 5 \%)$

$31(16 \cdot 2 \%)$

Use of local herbs

$20(10 \cdot 4 \%)$

A total of $2178(39 \cdot 0 \%)$ households had a home stock of pharmaceutical drugs at the time of the survey; 1800 households $(82 \cdot 6 \%)$ stocked paracetamol, $1854(85 \cdot 1 \%)$ chloroquine, $481(22 \cdot 1 \%)$ amodiaquine, $164(7 \cdot 5 \%)$ Fansidar (SP), $66(3 \cdot 0 \%)$ ampicillin capsules while $60(2 \cdot 8 \%)$ stocked drugs whose names they did not know. It was common to find a household stocking more than two drugs. For example, $594(27 \cdot 3 \%)$ households stocked both paracetamol and chloroquine (Table 3).

Household ownership of ITNs was assessed and found to be low - $546(9 \cdot 8 \%)$. Respondents were asked which people used the nets. Use of these nets a day before the survey was as follows: husband, $12 \cdot 3 \%$; husband and wife, $42 \cdot 1 \%$; wife and child, $19 \cdot 6 \%$; children, $26 \cdot 0 \%$. A few households $(86,1 \cdot 5 \%)$ had indoor residual spraying (data not shown).

\section{Factors associated with malaria at the household level}

Households that owned a bicycle and those that owned a radio reported less malaria among children $(\mathrm{OR}=0 \cdot 23, p<0 \cdot 0001$, and $\mathrm{OR}=0 \cdot 21, p<0 \cdot 0001$, respectively). Similarly, households with a clean compound and those using ITNs reported less malaria among children $(\mathrm{OR}=0.28, p<0.01$ and $\mathrm{OR}=0.28, p<0 \cdot 04$, respectively). Households that had stocked drugs for self-treatment of malaria and other illnesses reported less morbidity among children $(\mathrm{OR}=0.23, p<0 \cdot 0001)$ (Table 4$)$.

Factors associated with households that reported pregnant women with malaria are presented in Table 4 . One variable identified by all three models as protective for 
Table 3. Types of drugs stocked at the household level for treating malaria and any other illnesses

$\begin{array}{ll}\text { Drugs stocked }^{\mathrm{a}} & \text { No. households }\end{array}$

Paracetamol

Chloroquine

Amodiaquine

SP (Fansidar)

Ampicillin

Name of drug not known

Households with both paracetamol and chloroquine

Total households stocking a drug

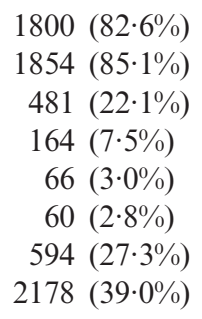

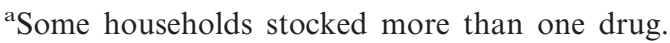

Table 4. Factors associated with malaria at the household level

\begin{tabular}{lccc}
\hline Covariate & Odds ratio & $95 \% \mathrm{CI}$ & $p$ \\
\hline & & \\
Dependent variable 'households reporting any case of malaria' & & \\
Ownership of bicycle & $0 \cdot 12$ & $0 \cdot 04-0 \cdot 195$ & $0 \cdot 001$ \\
Stocking drugs at home & $0 \cdot 23$ & $0 \cdot 16-0 \cdot 30$ & $0 \cdot 0001$ \\
Sleep under ITN & $0 \cdot 14$ & $0 \cdot 3-0 \cdot 24$ & $0 \cdot 01$ \\
Remove stagnant water & $0 \cdot 08$ & $0 \cdot 002-0 \cdot 16$ & $0 \cdot 04$ \\
Presence of eaves on house & $1 \cdot 4$ & $0 \cdot 4-2 \cdot 7$ & $0 \cdot 013$ \\
Number of people sleeping per room & $2 \cdot 1$ & $1 \cdot 7-2 \cdot 0$ & $0 \cdot 007$ \\
Dependent variable 'households reporting a child & with malaria' & & \\
Ownership of radio & $0 \cdot 21$ & $0 \cdot 09-0 \cdot 33$ & $0 \cdot 0001$ \\
Ownership of bicycle & $0 \cdot 23$ & $0 \cdot 13-0 \cdot 33$ & $0 \cdot 0001$ \\
Stocking drugs at home & $0 \cdot 23$ & $0 \cdot 14-0 \cdot 34$ & $0 \cdot 0001$ \\
Clean compound & $0 \cdot 28$ & $0 \cdot 06-0 \cdot 49$ & $0 \cdot 01$ \\
Sleep under ITN & $0 \cdot 28$ & $0 \cdot 01-0 \cdot 23$ & $0 \cdot 04$ \\
Presence of eaves on house & $3 \cdot 1$ & $1 \cdot 4-4 \cdot 7$ & $0 \cdot 001$ \\
Number of people sleeping per room & $4 \cdot 4$ & $3 \cdot 5-5 \cdot 2$ & $0 \cdot 0001$ \\
Dependent variable 'households reporting a pregnant woman with malaria' & \\
Sleep under ITN & $0 \cdot 26$ & $0 \cdot 02-0 \cdot 49$ & $0 \cdot 008$ \\
Stocking drugs at home & $0 \cdot 21$ & $0 \cdot 05-0 \cdot 37$ & $0 \cdot 0001$ \\
Clean compound & $0 \cdot 61$ & $0 \cdot 36-0 \cdot 87$ & $0 \cdot 0001$ \\
Remove stagnant water & $0 \cdot 28$ & $0 \cdot 11-0 \cdot 43$ & $0 \cdot 001$ \\
Presence of eaves on house & $4 \cdot 7$ & $1 \cdot 4-8 \cdot 0$ & $0 \cdot 005$ \\
& & & \\
\hline
\end{tabular}

malaria morbidity at the household level was using ITNs: for all households that reported a case of malaria, $\mathrm{OR}=0 \cdot 14(p<0 \cdot 01)$; for households that reported children having malaria, $\mathrm{OR}=0.28(p<0.04)$; and for households reporting pregnant women having malaria, $\mathrm{OR}=0 \cdot 26(p<0 \cdot 008)$ (Table 4$)$. 


\section{Perceptions on malaria illness, treatment and prevention practices}

Using KIs, most respondents described malaria as the most serious health problem in this community. Pregnant women and children were identified as the most vulnerable. The most common form of treatment for malaria was self-treatment with home-stocked drugs; and if this failed then visiting health units was the second resort. All respondents acknowledged that poor access to health services was most influenced by high costs, long distances and unavailability of drugs at health units, in that order. The high cost of ITNs was mentioned as the major constraint to their use.

Most respondent (about nine out of ten) said that most people in this area kept drugs to be used in emergency cases, while others kept drugs for fear that these might get depleted at drugs shops and they have to keep some in case a member of the household gets sick. As mentioned above, one of the compelling reasons for self-medication is an assessment of cost of seeking care at health units compared with self-treatment. Most key informants (about eight out of ten) mentioned that self-medication is cheaper, especially in rural areas where the malaria burden is high. The common resort of treatment in this area is self-treatment with home-stocked drugs or drugs bought from drug shops; and when the diseases do not get cured, then people visit health units for effective treatment and specialized care. The expression below by one of the key informants summarizes the reasons why people resort to self-treatment:

\footnotetext{
I keep drugs in my house; you can see that we are very far from the health unit. In case of any disease, it is easier and cheaper to use these drugs than walking to the health centre where there may be no help at all. Quite often there are no drugs or even the health worker may not be there. Even health workers charge money, yet we hear that services are supposed to be free. In such circumstances, we buy drugs and treat ourselves. (A community health worker at Buikwe)
}

The common sources of drugs for self-treatment were identified by most respondents (about nine out of ten) as drug shops, health units and pharmacies. The study sought to find out where people keep drugs. The commonest storage place was polythene bags followed by small envelopes, plastic tins, suitcases, metallic tins, wooden boxes and cupboards. Most respondents (about nine out of ten) said that in this community, drugs can be stocked in homes as long as one year. The respondents, especially community health workers, knew that this was dangerous and recommended that the government should facilitate them to create awareness on this issue.

The expression below was given by an opinion leader who explained how a neighbour's child died because of poorly stored drugs:

People who keep drugs at homes have no proper storage facilities for these drugs; that is why Nyombi's child died. The drugs were kept carelessly in the house and the child swallowed them and later died. (Opinion leader at Najjembe sub-county)

\section{Perceptions on expired drugs}

Because of the common practice of stocking drugs in homes and using them for self-treatment, perceptions on the issue of expired drugs were assessed. Many respondents (over three-quarters) in this community thought that expired drugs were dangerous. Expired drugs were thought to be poisonous and could cause the following illnesses: madness, cancer, ulcers, headache and stomach ache. However, 
few respondents (less than a quarter) were aware that expired drugs do not cure diseases. Respondents, especially drug-shop owners, said that some people were concerned about expired drugs, and these included students, teachers, policemen and those who were considered educated. On further probing, respondents said that most people in this community thought that drugs expired at drug shops and pharmacies but not in their homes. Few respondents (about two out of ten) blamed the government for not stopping people selling expired drugs. The extracts below summarize the perceptions on expired drugs in this community:

\footnotetext{
Expired drugs are a problem and I do not know why government does not help us and arrest all those people who sell expired drugs. The drugs kill people and they can cause other illnesses like ulcers and cancers. (An opinion leader at Ngogwe)

\begin{abstract}
Expired drugs is a big problem to us in rural areas, majority of people in this area do not bother to ask about when drugs expire, what matters to them is the price, if the drug is cheaper then they become happy and buy the drug without bothering to know how the drug will work (A local council official at Ngogwe)

Oh! Some few patients are very keen on expired drugs, they will ask you to show them a tin containing the drugs and try to read expiry date, If they do not see the expiry date then they suspect that you are selling expired drugs and they tell the whole village. People who are alert are mainly students, teachers, policemen and saved people. (A drug-shop owner at Buikwe)
\end{abstract}

This study further assessed people's concerns when they are purchasing pharmaceuticals. It was the general view of most respondents (about nine out of ten) that when people are purchasing drugs they always want to know the price of the drug and what it costs to treat a disease. The second concern is whether the drug is effective and cures the disease quickly. People are also interested in knowing whether people who sell the drugs are trained health workers so that they can buy genuine drugs. Few respondents (less than a tenth) were concerned with the appropriate dosage of the drug, how it works, side-effects and the expiry date of the drug. Most respondents (about nine out of ten) in this community did not link expired drugs to poor treatment of malaria. The expression below is from a community health worker who has experience with people in this community:

The major concern for people is getting cured quickly, and they ask for strong drugs no matter the side effects. (A community health worker at Ngogwe)

One of our major concerns is the price of the drug, we want to buy drugs which are cheap, and you know money is scarce these days. (A woman local council official at Buikwe)

\section{Discussion}

The study documents high self-reported malaria morbidity in the study area. Although the most common pattern of resort is self-treatment, an interesting finding is that some people know about expiry of drugs and its effect on malaria treatment. However, the major concern expressed by people purchasing drugs over-the-counter was the cost of the drug and its ability to resolve the illness very quickly. Few people asked about appropriate dosages, expiry dates and how these affected treatment of malaria. The results further show that household ownership of ITNs and use of indoor residual spraying were low, yet these are important tools for malaria 
prevention. One explanation is that the Ministry of Health had not yet embarked on the large-scale marketing of ITNs and indoor residual spraying as effective tools for malaria prevention. These are important findings that require a health promotion package to explain the benefits of effective case management of malaria and use of ITNs for malaria prevention. Issues of affordability need to be addressed, especially for ITNs.

The pattern of treatment for malaria identified in this study, where most households resort to self-treatment, is consistent with previous findings (McCombie, 1996; Uganda Bureau of Statistics, 2001, 2006; Heggenhougen, 2003). A similar pattern of resort among pregnant women has recently been documented in the study area (Mbonye et al., 2006). In this study, however, a bigger proportion of children are taken to private clinics and health units compared with pregnant women with malaria. It is important to explore this area further and assess this pattern of treatment seeking. Uganda has implemented a home-based management of fevers programme since 2002 (MOH, 2002); it would be interesting to find out how this strategy has influenced treatment seeking at health units.

This study's findings show that households stock chloroquine, SP and other drugs for treating omusujja. As there is widespread chloroquine and SP resistance reported in Uganda (Kamugisha et al., 1994; Talisuna et al., 2002; Dorsey et al., 2004; Bakyayita et al., 2005), the consequence of self-medication with chloroquine and SP will be to increased malaria morbidity and mortality. One explanation for the continued use of these drugs is that they still have some effect, otherwise people would realize this and look for alternative care. It is possible that the drugs have some antipyretic effect (especially for chloroquine and paracetamol) useful in treating malaria symptoms and some febrile illnesses. The Ministry of Health in Uganda currently recommends artemesinin-based combination therapy (ACTs); specifically, artemether/lumefantrine $\left(\mathrm{COARTEM}^{\circledR}\right)$ is the recommended first-line drug for malaria (MOH, 2005). This study was implemented before the current policy was put in place. Thus the results should be interpreted in this context. Similarly, few households with children reported to have malaria visited community health workers for malaria treatment (Table 2). This is probably because the home management of fevers policy had just started and was not implemented on a large scale (MOH, 2002).

The factors associated with malaria morbidity are shown in Table 4 . These can be grouped into socioeconomic factors (ownership of a bicycle and a radio), environmental hygiene factors (clean compound and removing stagnant water) and behavioural/care-seeking factors (stocking drugs and using ITNs). For all three models, using ITNs was protective for malaria. As previous studies have shown, ITNs are important in reducing malaria morbidity and mortality (Snow, 1988; Dolan et al., 1993; D'Alessandro et al., 1995). There is a need to advocate the use of ITNs and address the issues that limit their use, such as high cost, perception that ITNs have chemicals that have dangerous effects on pregnancy and children, and low antenatal care attendance and lack of interest in malaria prevention by husbands (Mbonye et al., 2006). Since behavioural variables such as cleaning compounds and clearing bushes may not be effective in malaria prevention, especially with Anopheles gambiae, effective case management and scale-up of ITNs could be prioritized. 
The limitation of this study is mainly the definition of malaria as omusujja gw'ensiri, which is used interchangeably with the local term omussujja as indicated earlier (Kengeya et al., 1994; Mbonye et al., 2006). Although the use of the term omusujja gw'ensiri is closer to malaria as a disease entity, there are no data on the reliability of this term. Recent data in Uganda have shown that the definition of malaria using clinical symptoms such as feeling hot with headache, joint pains and general weakness, has not been useful in diagnosing malaria in children aged less than 5 years (Kallander et al., 2004). Thus it is possible the prevalence of reported malaria episodes in this study is an overestimate. This is supported by recent findings in Kampala, which showed that $32 \%$ of febrile episodes are due to malaria (NjamaMeya et al., 2007). Although this is an urban setting, this could be the case in a nearby district like Mukono. Further, malaria morbidity was self-reported and was probably affected by memory recall of sickness events. It is also possible that there were differences in male and female responses to morbidity related to children due to their different levels of participation in care seeking. Finally, estimating morbidity based on households does not give accurate estimates of prevalence of malaria within the population.

Policy implications of these findings include scaling-up malaria treatment and prevention interventions by identifying innovative ways to increase access to ITNs and advocating for effective malaria case management. Explaining the benefits of effective case treatment of malaria through health education messages is important. This should advocate access to ACTs, which are the first-line treatment for malaria in Uganda. There is a need to initiate a policy dialogue between the Ministry of Healthy and the Ministry of Finance to discuss ways of increasing funding to the health sector to address health system issues such as availability of drugs for effective case management and subsidizing the cost of ITNs. It is also important to identify new approaches to scaling-up malaria prevention interventions such as ITNs through innovative community structures that could reach households easily.

\section{Acknowledgments}

This study was a collaboration between the Ministry of Health Uganda, and the DBL-Centre for Health Research and Development, Department of Veterinary Pathobiology, Faculty of Life Sciences, University of Copenhagen. It was funded by the Gates Malaria Partnership at the London School of Hygiene and Tropical Medicine.

\section{References}

Adome, R. O. \& Whyte, S. R. (1996) Popular Pills: Community Drug Use in Uganda. Het Spinhuis, Amsterdam.

Agyepong, I. A., Ansah, E., Gyapong, M., Adjei, S., Barnish, G. \& Evans, D. (2002) Strategies to improve adherence to recommended chloroquine treatment regimes: a quasi-experiment in the context of integrated primary health care delivery in Ghana. Social Science and Medicine 55(22), 15-26. 
Amuyunzu, M. K. (1998) Willing the spirits to reveal themselves: Rural Kenyan mothers' responsibility to restore their children's health. Medical Anthropology Quarterly 12(4), 490-502.

Anyama, N. \& Adome, R. O. (2003) Community pharmaceuticals care: an 8 month critical review of two pharmacies in Kampala. African Health Sciences 3, 87-93.

Bakyaita, N., Dorsey, Yeka, A., Banek, K., Staedke, S. G., Kamya, M. et al. (2005) Sulphadoxine-pyrimethamine plus chloroquine or amadiaquine for uncomplicated Falciparum malaria: a randomised, multisite trial to guide national policy in Uganda. American Journal of Tropical Medicine and Hygiene 72, 573-580.

Brown, P. J. (1997) Culture and the global resurgence of malaria. In Inhorn, M. C. \& Brown, P. J. (eds) The Anthropology of Infectious Diseases: International Health Perspectives, 2nd edition. Amsterdam, Gordon and Breach Science Publishers, pp. 119-141.

D’Alessandro, U., Olaleye, B. O., McGuire, Thomson, M. C., Langerock, P. \& Greenwood, B. M. (1995) A comparison of the efficacy of insecticide-treated nets and untreated nets in preventing malaria in Gambian children. Transactions of the Royal Society of Tropical Medicine and Hygiene 89, 596-598.

Demming, M. S. (1989) Home treatment of febrile children with antimalaria drugs in Togo. Bulletin of the World Health Organization 67, 695-700.

Dolan, G., ter Kuile, F., Jacoutot, V. et al. (1993) Bed nets for the prevention of malaria and anaemia in pregnancy. Transactions of the Royal Society of Tropical Medicine and Hygiene 87, 620-626.

Dorsey, G., Dokomajilar, C., Kiggundu, M., Staedke, S. G., Kamya, M. R. \& Roseenthal, P. J. (2004) Principal role of dihydropteroate synthase mutations in mediating resistance to sulfadoxine-pyremethamine in single-drug and combination therapy of uncomplicated malaria in Uganda. American Journal of Tropical Medicine and Hygiene 71, 758-763.

Foster S. (1991) The distribution and use of antimalarial drugs - not a pretty picture. In Targett, G. A. T. (ed) Malaria: Waiting for the Vaccine. John Wiley and Sons, Chichester, pp. $120-140$.

Foster, S. (1995) Pricing, distribution and use of antimalarial drugs. Bulletin of the World Health Organization 69, 349-363.

Heggenhougen, H. K., Hackenthal, V. \& Vivek, P. (2003) The Behaviour and Social Aspects of Malaria Control: An Introduction and Annotated Biography. Special program for research and training in tropical diseases. TDR, WHO, Geneva.

Igun, U. A. (1987) Why we seek treatment here: retail pharmacy and clinical practice in Maiduguri, Nigeria. Social Science and Medicine 8, 689-695.

Kallander, K., Nsungwa-Sabiiti et al. (2004) Symptom overlap for malaria and pneumonia policy implications for home management strategies. Acta Tropica 90, 211-214.

Kamugisha, J., Kipp, W. \& Burnham, G. (1994) In vivo sensitivity of Plasmodium falciparum to choloroquine, amodiaquine and Sulphadoxine-pyrimethamine in Western Uganda. Tropical Geographical Medicine 46, 364-365.

Kengeya, J. K., Seeley, J. A., Kajura-Beganja, E., Kabunga, E., Mubiru, E., Sembaja, F. \& Mulder, D. W. (1994) Recognition, treatment seeking behaviour and perception of cause of malaria among rural women in Uganda. Acta Tropica 58, 267-273.

Lee, P. \& Herzstein, J. (1986) Drug regulation. Annual Review of Public Health, pp. 217-219.

McCombie, S. C. (1996). Treatment seeking for malaria: A review of recent research. Social Science and Medicine 6, 933-945.

Mbonye, A. K., Neema, S. \& Magnussen, P. (2006) Treatment seeking practices among pregnant women in Mukono District, Uganda. Journal of Biosocial Science 38, 221-237.

MOH (1999) The National Health Policy. Ministry of Health, Kampala, Uganda. 
MOH (2000) Health Sector Strategic Plan I (2000-2005). Ministry of Health, Kampala, Uganda.

MOH (2002) Implementing Guidelines for the National Home Based Management of Fever Strategy. Ministry of Health, Kampala, Uganda.

MOH (2003) Clinical Guidelines: National Guidelines on Management of Common Conditions. Ministry of Health, Kampala, Uganda.

MOH (2005) A Review of the Situation of Malaria Prevention and Control in Uganda. Ministry of Health, Kampala, Uganda.

MOH (2006) Uganda Malaria Control Strategic Plan, 2005/06-2009/10. Ministry of Health, Kampala, Uganda.

Mwenesi, H. A., Harpharm, T. T. \& Snow, R. W. (1995) Child malaria treatment practices among mothers in Kenya. Social Science and Medicine 40, 1271-1277.

Njanma-Meya, D., Clark, D. et al. (2007) Treatment of malaria restricted to laboratoryconfirmed cases: a prospective cohort study in Uganda. Malaria Journal 6, 7.

Nshakira, N., Kristensen, M., Ssali, F. \& Whiye, R. (2002) Appropriate treatment of malaria? Use of antimalarial drugs for children's fevers in district medical units, drug shops and homes in Eastern Uganda. Tropical Medicine and International Health 7, 309-316.

Nyamongo, I. K. (2002) Health care switching behaviour of malaria patients in a Kenyan rural community. Social Science and Medicine 54(3), 377-386.

RBM (2000) Scaling Up Insecticide-Treated Netting (ITN) Programs in Africa: A Strategic Framework for Coordinated National Action. Roll Back Malaria, WHO, Geneva.

Snow, R. W. (1988) A trial of bed nets (mosquito nets) as a malaria control strategy in a rural area of the Gambia, West Africa. Transactions Royal Society of Tropical Medicine and Hygiene 82, 212-215.

Steketee, R. W., Wirima, J. J., Hightower, A. W., Slutsker, L., Heyman, D. L. \& Breman, J. G. (1996) The effect of malaria and malaria prevention in pregnancy on offspring birth weight, prematurity and intrauterine growth retardation in rural Malawi. American Journal of Tropical Medicine and Hygiene 55, 33-41.

Talisuna, A. O., Langi, P., Bakyayita, N., Egwang, T., Mutabingwa, T. K., Walkins, W., Van Marck, E. \& D'Alesandro, U. (2002) Intensity of malaria transmission, antimalaria-drug use and resistance in Uganda: what is the relationship between these factors? Transactions of the Royal Society of Tropical Medicine and Hygiene 96, 310-317.

Trape, J. F. (1987) Malaria and urbanisation in central Africa: the example of Brazzaville. Description of the town and review of previous surveys. Transactions of the Royal Society of Tropical Medicine and Hygiene 81 (supplement 2), 1-9.

Uganda Bureau of Statistics (2002) The Statistical Abstract. Uganda Bureau of Statistics, Entebbe, Uganda.

Uganda Bureau of Statistics (2001) The Uganda Demographic and Health Survey. Uganda Bureau of Statistics, Entebbe, Uganda.

Uganda Bureau of Statistics (2006) The Uganda Demographic and Health Survey. Preliminary Report. Uganda Bureau of Statistics, Entebbe, Uganda. 